\title{
Growth and Magnetic Properties of RF Sputtered Fe-Ga Thin Films
}

\author{
Lalitha Raveendran Nivedita ${ }^{a}$, Valiveti Venkata Siva Kumar ${ }^{b}, K_{a n d a s a m i ~ A s o k a n}{ }^{b}$, \\ Ramasamy Thangavelu Rajendrakumar ${ }^{a, c} *$ \\ aAdvanced Materials and Devices Laboratory, Department of Physics, Bharathiar University, \\ Coimbatore, India Pin - 641046 \\ ${ }^{b}$ Materials Science Division, Inter University Accelerator Centre, New Delhi, India Pin -110 067 \\ 'Department of Nanoscience and Technology, Bharathiar University, Coimbatore, India Pin - 641046
}

Received: November 11, 2014; Revised: February 7, 2015

\begin{abstract}
We report the growth and characterization of Fe-Ga thin films. These films were RF sputtered onto $\mathrm{Si}, \mathrm{MgO}$ and quartz substrates by controlling the parameters such as the deposition time, power and substrate temperature. The deposited films were characterized using X-Ray Diffraction, Atomic Force Microscopy and Vibration Sample Magnetometry measurements. The effect of substrates on the structure and magnetic properties were studied. XRD pattern of the deposited films showed the formation of $\mathrm{DO}_{3}$ phase with $\mathrm{L}_{2}$ ordered structure at higher sputtering power. The room temperature deposited films demonstrated higher magnetization $(0.08 \mathrm{emu} / \mathrm{g})$ as compared to higher substrate temperature $\left(300{ }^{\circ} \mathrm{C}\right)$ deposited films. The $\mathrm{M}_{\mathrm{r}} / \mathrm{M}_{\mathrm{s}}$ ratio was found to be 0.037 for films deposited at room temperature and 0.009 for the substrate temperature $300{ }^{\circ} \mathrm{C}$. $\mathrm{L}_{2}$ order was observed in films deposited on $\mathrm{MgO}$ and Quartz substrates. Magnetization was also found to be high $\left(\mathrm{M}_{\mathrm{s}}\right.$ out of plane $=518 \mathrm{emu} / \mathrm{cm}^{3}, \mathrm{M}_{\mathrm{s}}$ in plane $=707 \mathrm{emu} / \mathrm{cm}^{3}$ ) for films deposited on $\mathrm{MgO}$ substrate .
\end{abstract}

Keywords: $\mathrm{Fe}$-Ga thin films, RF sputtering, annealing, in plane magnetization, out plane magnetization, lattice rearrangement

\section{Introduction}

Magnetostrictive thin films with lower saturation field and coercivity; and higher magnetostriction coefficient have applications in magnetic micromechanical systems ${ }^{1}$. Since its inception into the world of advanced functional material research, FeGa alloys have gained much popularity and piqued the interest amongst the scientific community owing to their superior mechanical and magnetostrictive properties on comparison with its already in market counterparts like Terfenol-D and shape memory alloys. There are five phases that can co-exist in the FeGa alloys and thin films, namely, a disordered bcc $\alpha-$ Fe phase (A2), an ordered bcc superlattice phase $\left(\mathrm{DO}_{3}\right)$, an ordered fcc phase $\left(\mathrm{Ll}_{2}\right)$, an ordered hexagonal close packed phase $\left(\mathrm{DO}_{19}\right)$ and an ordered bcc phase (B2) as per the currently available literature. The presence of $\mathrm{DO}_{3}$ structure is said to be detrimental for obtaining high magnetostrictive property of FeGa alloys or films $\mathrm{s}^{2,3}$. It is proposed that one could extract maximum magnetostriction from these materials when it has A2 phase $^{4}$. For magnetostrictive devices, magnetoelastic material in the form of thin films with high magnetostriction constant and low saturation field are desired. There are many results on single crystalline and polycrystalline bulk Galfenol with varying compositions. Gaudet et. al. ${ }^{3}$, have prepared $\mathrm{Fe}_{100-\mathrm{x}} \mathrm{Ga}_{\mathrm{x}}$ alloys by mechanical milling and reports low degree of $\mathrm{Ga}$ clustering in as milled powders which is indicative to the

*e-mail: rtrkumar@buc.edu.in commencement of short range $\mathrm{DO}_{3}$ ordering and shows the formation of $\mathrm{DO}_{3}$ and $\mathrm{L}_{2}$ order in annealed samples. Basumatary et. al. ${ }^{5}$ have also reported the presence of all the three phases $\left(\mathrm{A} 2, \mathrm{DO}_{3}, \mathrm{~L}_{2}\right)$ in FeGa alloy. Zhang et. al. ${ }^{6}$, found the $\mathrm{DO}_{3}$ structure and Ga-rich cluster formation in melt spun ribbons which enhanced their giant magnetostriction. Limited literature is available on RF sputtered galfenol thin films ${ }^{1}$. Morley et. al. ${ }^{7}$, prepared FeGa thin films of varying compositions using a customised deposition procedure using both co-sputtering and evaporation process. This was done to facilitate flexibility in the film composition by varying the evaporation rate and sputtering power of the target. Javed et. al. ${ }^{8}$, successfully deposited single phase b.c.c. FeGa thin films which had weak uniaxial anisotropy at lower Ar pressure and exhibited isotropic nature on increased $\mathrm{Ar}$ pressure. However, there was no change in magnetostriction constant with respect to varying pressure. Butera et. al. ${ }^{9,10}$, have successfully grown FeGa films with cubic magnetic symmetry on $\mathrm{MgO}$ substrates. Basantkumar et. al. ${ }^{1}$, fabricated FeGa films on thin glass cover slides using RF sputtering and studied how the forward power affects its composition and magnetic properties. These groups also succeeded in integrating these films with MEMS cantilevers for magnetic actuation. Present study attempts to fabricate Galfenol thin films by RF sputtering on different substrates varying the deposition parameters and understanding their structural and magnetic properties. 


\section{Experimental Methodology}

Thin Films of FeGa were prepared by RF Magnetron sputtering under different deposition conditions. The RF sputtering unit was a custom made instrument in the Inter University Accelerator Centre (IUAC), New Delhi. The films were prepared at different conditions by varying sputtering parameters such as sputtering power and substrate temperature. FeGa alloy 2" diameter target was RF sputtered with power $\mathrm{P}_{\mathrm{Sp}}$, which was varied as $80,100,120$ and $140 \mathrm{~W}$. The typical base chamber pressure was $6.5 \times 10^{-5}$ torr and the argon working pressure was kept constant for all depositions at $6.5 \times 10^{-2}$ torr. The films were deposited onto Si substrates at room temperature and at $300{ }^{\circ} \mathrm{C}$ by varying the time of deposition and substrate temperature along with sputter power. By varying the time of deposition as $45 \mathrm{~min}, 90 \mathrm{~min}$ and $180 \mathrm{~min}$, we obtained films of thickness $\sim 20 \mathrm{~nm}, \sim 40 \mathrm{~nm}$, $\sim 100 \mathrm{~nm}$. $20 \mathrm{~nm}$ films were deposited at all the four $\mathrm{P}_{\mathrm{Sp}}$ at both room temperature and $300{ }^{\circ} \mathrm{C}, 40 \mathrm{~nm}$ films at $\mathrm{P}_{\mathrm{Sp}}$ of $100 \mathrm{~W}$ at room and $300^{\circ} \mathrm{C}$ substrate temperature and $100 \mathrm{~nm}$ films at $\mathrm{P}_{\mathrm{Sp}} 80 \mathrm{~W}$ and $140 \mathrm{~W}$ at room and $300{ }^{\circ} \mathrm{C}$ substrate temperature. The structural analysis of the films was done by taking their $2 \theta \mathrm{X}$-Ray scans using glancing incidence X-ray diffractometer (GIXRD), Bruker, D-8 model and Surface morphology analysis was done by Atomic Force Microscopy (AFM), Veeco Instruments Inc.. Magnetic properties of these films were measured by Vibration Sample Magnetometer (VSM), EV-9, Microsense.

\section{Results and Discussion}

The XRD pattern of the alloy target had two main peaks with (110) reflection at $43.6^{\circ}$ and (200) reflection at $63.4^{\circ}$ that corresponds to $\mathrm{A} 2$ structure. Though this is the most likely crystal structure, it could also be that of $\mathrm{DO}_{3}$ $\left(\mathrm{Fe}_{3} \mathrm{Al}\right.$ type, $\left.\alpha "\right)$, which have X-ray diffraction reflections at (220) for $43.6^{\circ}$ peak and (400) for $63.4^{\circ[2,11]}$, since the alloy composition is in the range of 25 between 25 and $30 \%$. The same peaks were expected in the sputtered films also. But the XRD showed a predominant peak at $\sim 52^{\circ}$ in all the films deposited at different sputtering powers. There were some other reflections present along with this predominant peak under selected sputtering conditions.

The XRD $2 \theta$ scans of $20 \mathrm{~nm}, 40 \mathrm{~nm}$ and $100 \mathrm{~nm}$ thick films fabricated by varying $\mathrm{P}_{\mathrm{Sp}}$ were taken. For $20 \mathrm{~nm}$ and $40 \mathrm{~nm}$ thick films, two peaks were observed at $\sim 52^{\circ}$ and $\sim 55^{\circ}$ corresponding to the (311) and (222) reflections originating from $\mathrm{DO}_{3}$ ordering. The high intensity reflection at $\sim 52^{\circ}$ clearly identifies the presence of $\mathrm{DO}_{3}$ ordering ${ }^{2,6}$. The (222) reflection is of much less intensity. From all the films deposited on $\mathrm{Si}$ at various $\mathrm{P}_{\mathrm{Sp}}$ 's, we have concentrated on $100 \mathrm{~nm}$ thick films under extreme $\mathrm{P}_{\mathrm{Sp}}$ conditions, namely, $80 \mathrm{~W}$ and $140 \mathrm{~W}$. The films deposited at other conditions were not uniform. Figure 1 shows the XRD patterns of $100 \mathrm{~nm}$ thick films fabricated at two $\mathrm{P}_{\mathrm{Sp}}, 80 \mathrm{~W}$ and $140 \mathrm{~W}$. We observed the presence of $\mathrm{DO}_{3}$ structure in all the films. Room temperature prepared films deposited at both the $\mathrm{P}_{\mathrm{Sp}}$ demonstrates the presence of the (311) reflection while (222) reflection is absent in higher $\mathrm{P}_{\mathrm{Sp}}$ deposited film. There is evolution of a peak at $\sim 35^{\circ}$ in these films, which corresponds to that of (110) reflection of $\mathrm{L}_{2}$. Sputtering at higher $\mathrm{P}_{\mathrm{Sp}}$ could have resulted in mixed phase formation of $\mathrm{FeGa}$, with both $\mathrm{L}_{2}$ and $\mathrm{DO}_{3}$ structure presence in the film. The above mentioned room temperature deposited films were annealed in vacuum for three hours at $500{ }^{\circ} \mathrm{C}$. The (110) reflection was found to completely vanish after annealing. This indicates the probable rearrangement of lattice system of $\mathrm{FeGa}$ where $\mathrm{L}_{2}$ phase gets rearranged to form $\mathrm{DO}_{3}$. The crystallite size calculated using Debye-Scherrer formula was in the range of $75-90 \mathrm{~nm}$ for all the films. There was substantial increase in the crystallite size $(\sim 135 \mathrm{~nm})$ after the films were annealed. We have optimised the ambient deposition condition for the films on Silicon to be $140 \mathrm{~W}$ with $300{ }^{\circ} \mathrm{C}$ substrate temperature for a deposition time of $180 \mathrm{~min}$, because it delivers uniform and homogenous films.

There are various reports of FeGa films deposited onto metallic underlayers ${ }^{9,12-14}$ and substrates other than $\mathrm{Si}$ and glass. After optimisation, a set of films were deposited on $\mathrm{MgO}$ and Quartz substrates along with $\mathrm{Si}$, at $\mathrm{P}_{\mathrm{Sp}} 140 \mathrm{~W}$, $300{ }^{\circ} \mathrm{C}$ substrate temperature for $180 \mathrm{~min}$ to see how substrate affects the films. The films were approximately $100 \mathrm{~nm}$ thick. The as-prepared films were also annealed in vacuum at $500{ }^{\circ} \mathrm{C}$ for three hours. The XRD scans of the as-prepared and annealed films are given in Figure $2 a$ and $b$.

The film deposited on Si substrate had (311) reflection of $\mathrm{DO}_{3}$ which was the predominant peak. The other reflections at $\sim 35^{\circ}$ and $\sim 62^{\circ}$ with (110) and (211) orientations identify the presence of partial $\mathrm{L}_{2}$ ordering in the film. There is also the presence of a reflection at $\sim 55^{\circ}$ which could be either (222) orientation of $\mathrm{DO}_{3}{ }^{[2]}$ or (210) orientation of $\mathrm{L}_{2}$ ordering ${ }^{2}$. The films on Quartz substrate exhibits only (110) and (211) reflections of $\mathrm{L}_{2}$. The dominant reflection on $\mathrm{MgO}$ substrate is at $\sim 43^{\circ}$ which belongs to (111) reflection of $\mathrm{L} 1_{2}$. The only other peak corresponds to (211) orientation of $\mathrm{L} 1$.

The X-ray data of films on different substrates (Figure 2) confirms the partial long range ordering of $\mathrm{DO}_{3}$ and $\mathrm{L}_{2}$ structures on different substrates. While $\mathrm{Si}$ is the only substrate that favours the development of $\mathrm{DO}_{3}$ long range order (though with the presence of $\mathrm{L}_{2}$ order), $\mathrm{MgO}$ and Quartz substrate favours the film deposition in $\mathrm{Ll}_{2}$ ordered structure. The $\mathrm{L} 1_{2}(110)$ and (211) reflections in annealed film on Quartz substrate slightly improves in intensity with

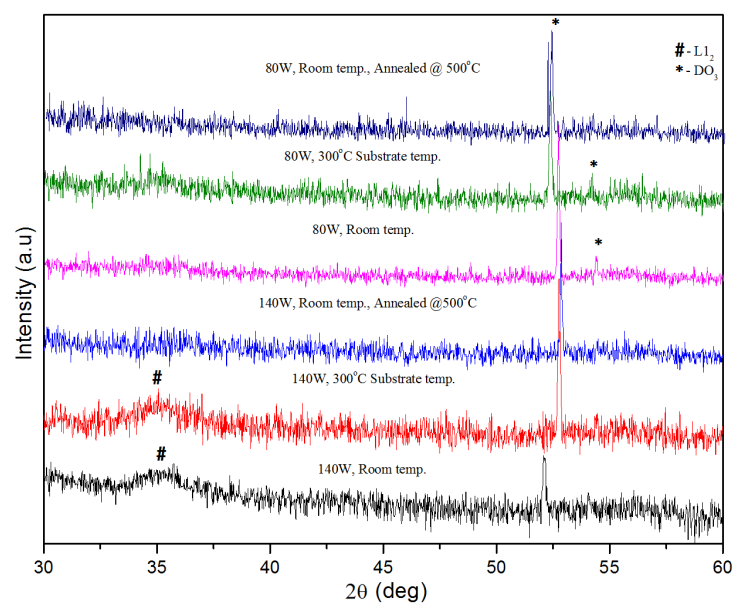

Figure 1. X-Ray diffraction patterns of $100 \mathrm{~nm}$ thick FeGa thin films deposited at Room temperature and $300{ }^{\circ} \mathrm{C}$ substrate temperature. 


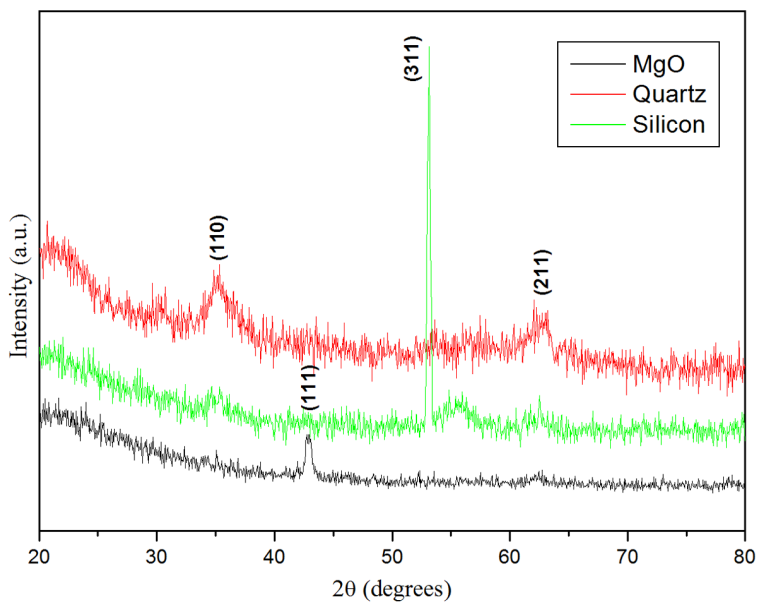

(a)

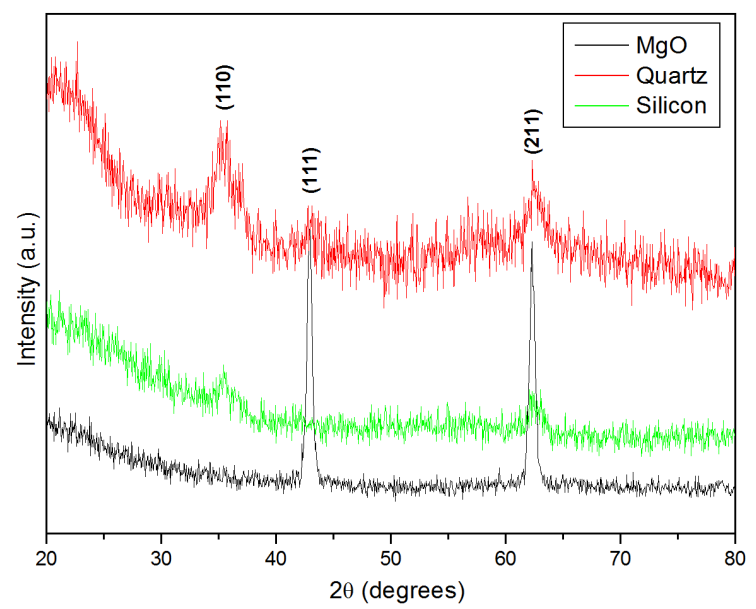

(b)

Figure 2. X-Ray diffraction patterns of FeGa thin films on different substrates a) as-deposited b) annealed at $500{ }^{\circ} \mathrm{C}$.

a shift of $0.2^{\circ}$ to higher $2 \theta$ value while they show a shift of $\sim 0.1^{\circ}$ to the lower $2 \theta$ value in Si substrate with the complete disappearance of the previously dominant $\mathrm{DO}_{3}$ reflection. The disappearance of $\mathrm{DO}_{3}$ reflection can only mean that lattice rearrangement occurred. But this is at total contradiction with the result from what we observed in the room temperature deposited films. There, the lattice rearrangements lead to complete formation of $\mathrm{DO}_{3}$ whereas, here the inverse effect is observed. The shift in the peak $2 \theta$ value can also be attributed to the lattice rearrangements. The $\mathrm{L}_{2}$ reflections of FeGa on $\mathrm{MgO}$ increases in intensity on annealing which manifests betterment of crystallinity of the film.

The calculation of microstrain on films (Table 1) due to the substrate was carried out and it was found that the films on $\mathrm{MgO}$ substrates indicated low strain thus manifesting the fact that it may be a better suited substrate for the nucleation and growth of thin films. The microstrain on quartz and Silicon substrates were 3 times greater when compared with $\mathrm{MgO}$. The microstrain was calculated for the dominant peak present in the films in each substrate. The earlier reports mentioning that the lattice mismatch is minimal for $\mathrm{FeGa} / \mathrm{MgO}$ is affirmed by the minimal strain in thin films.

The surface morphology of the deposited thin films was observed using Atomic Force Microscopy. Figure 3 shows the AFM images of the as-deposited and annealed $100 \mathrm{~nm}$ thick FeGa thin films. The films deposited were uniform and the line scans across the AFM images gave the average grain diameter to be in the range of 75-120 $\mathrm{nm}$ in as deposited films while it was $45-55 \mathrm{~nm}$ in annealed thin films.

It was seen from XRD that the grain size increased on annealing the as deposited film. But this was contrary to what we observed in AFM data. The grain size here reduced drastically from $\sim 110$ to $\sim 55 \mathrm{~nm}$. It can be inferred that there is columnar grain growth during annealing. The variation in grain size could be due to the presence of inhomogeneous strains in the film ${ }^{8}$. The RMS values of the surface roughness of the films were below $2 \mathrm{~nm}$.

The M-H hysteresis loops for the $100 \mathrm{~nm}$ thick films (140W) fabricated on Si substrates are shown in Figure 4.
Table 1. The microstrain values calculated from Fe-Ga thin films on different substrates.

\begin{tabular}{lccc}
\hline \multirow{2}{*}{ Substrate } & \multicolumn{3}{c}{ Microstrain $\left(\mathbf{x 1 0 ^ { - 3 } )}\right.$} \\
\cline { 2 - 4 } & As prepared & Annealed & $\begin{array}{c}\text { As prepared / } \\
\text { annealed }\end{array}$ \\
\hline $\mathrm{MgO}$ & 2.7248 & 1.7278 & 1.5770 \\
Silicon & 8.3445 & 2.0556 & 4.0594 \\
Quartz & 8.01 & 4.2496 & 1.8849 \\
\hline
\end{tabular}

Both room temperature and $300{ }^{\circ} \mathrm{C}$ substrate temperature deposited films demonstrate soft magnetic property.

The room temperature deposited films showed higher saturation magnetisation $(0.08 \mathrm{emu} / \mathrm{g})$ than the higher substrate temperature deposited films $(0.06 \mathrm{emu} / \mathrm{g})$. The coercivity of films deposited at room temperature is $87.697 \mathrm{G}$ with $\mathrm{M}_{\mathrm{r}} \mathrm{M}_{\mathrm{s}}$ ratio of 0.03724 while for higher substrate temperature deposited film, coercivity is $12.809 \mathrm{G}$ and the $\mathrm{M}_{\mathrm{r}} / \mathrm{M}_{\mathrm{s}}$ ratio is 0.00918 .

The hysteresis loops for the films deposited on different substrates are plotted in Figure 5. The effect of substrate on M of the films manifests in as deposited films. The magnetization is highest for films on $\mathrm{MgO}$ with $\mathrm{M}_{\mathrm{s} / /}=512 \mathrm{emu} / \mathrm{cm}^{3}$ and $M_{\mathrm{s}} \perp=699 \mathrm{emu} / \mathrm{cm}^{3}$ (Refer Table 2). Magnetization of films deposited on Si and Quartz substrates are in the similar range. On annealing, the overall magnetization reduces with its value being comparable in all substrates, though a slight higher $\mathrm{M}_{\mathrm{s}} \perp$ value is observed for quartz. The $\mathrm{M}_{\mathrm{s}} \perp / \mathrm{M}_{\mathrm{s} / /}$ ratio was found to be more or less the same for $\mathrm{MgO}$ and Si substrate whereas this is much higher for quartz.

The hysteresis loops for films deposited on different substrates for both as deposited and annealed conditions were plotted as in Figure 6. It is observed that the magnetisation value is higher for as-deposited film on $\mathrm{MgO}$. On annealing, the magnetization of film decreases in both in plane and out of plane directions. The magnetization values improve after annealing for films on Quartz and Silicon. For fcc $\mathrm{L}_{2}$ order, the easy axis of magnetization is (111) which is present in the films deposited on $\mathrm{MgO}$ substrate. The higher value 


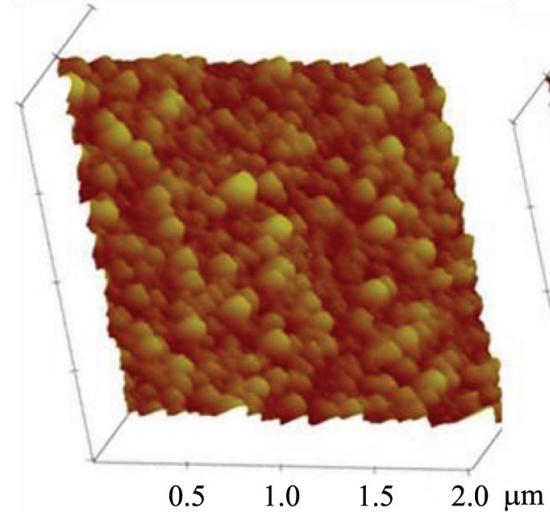

(a)

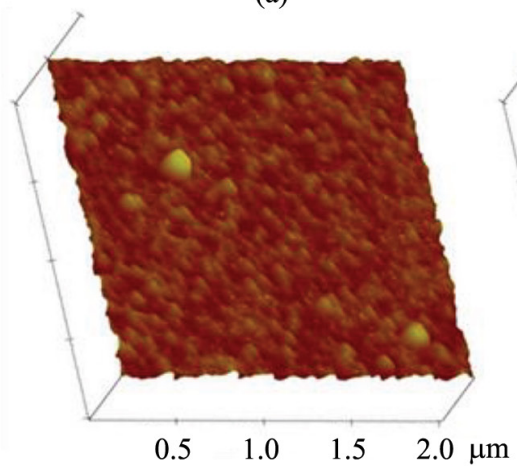

(d)

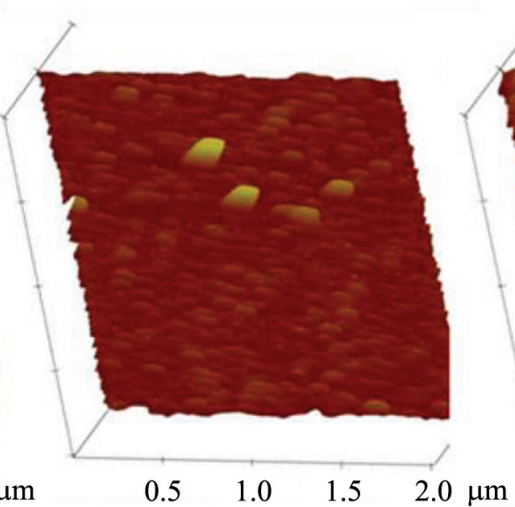

(b)

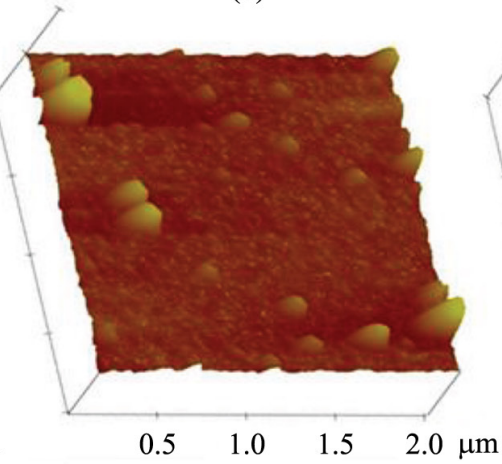

(e)

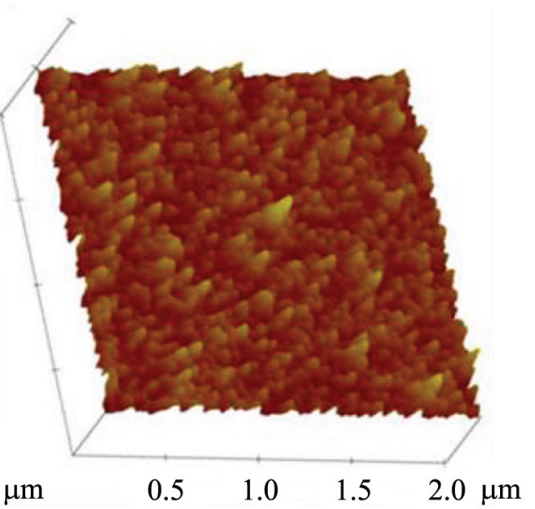

(c)

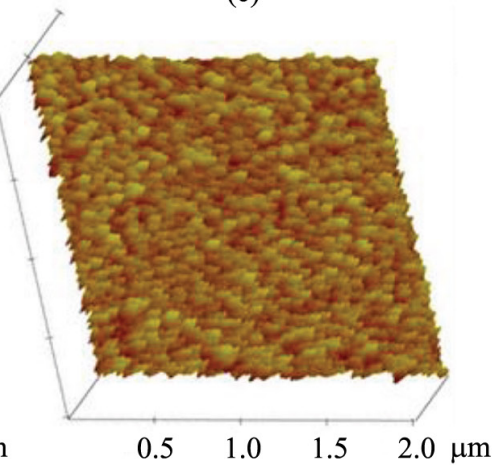

(f)

Figure 3. a) AFM images of FeGa thin films deposited at $140 \mathrm{~W}$ at a) Room temperature b) $300{ }^{\circ} \mathrm{C}$ substrate temperature c) $140 \mathrm{~W}$ Annealed (a) $500{ }^{\circ} \mathrm{C}$ for three hours d) $80 \mathrm{~W}$ deposited at Room temperature e) $300^{\circ} \mathrm{C}$ substrate temperature f) $80 \mathrm{~W}$ Annealed @ $500{ }^{\circ} \mathrm{C}$ for three hours.

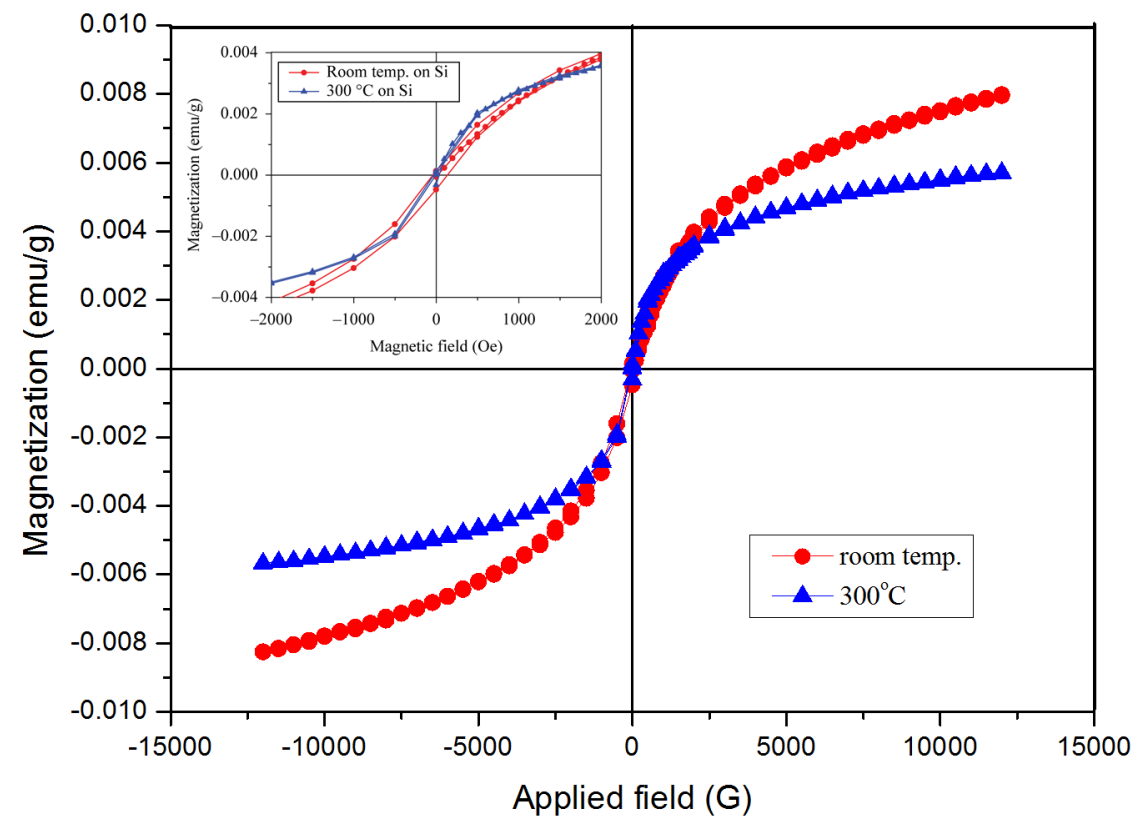

Figure 4. Magnetic field dependence of Magnetisation of as-deposited (140W) FeGa thin films on Si substrate. In the inset, we have the zoomed in view. 


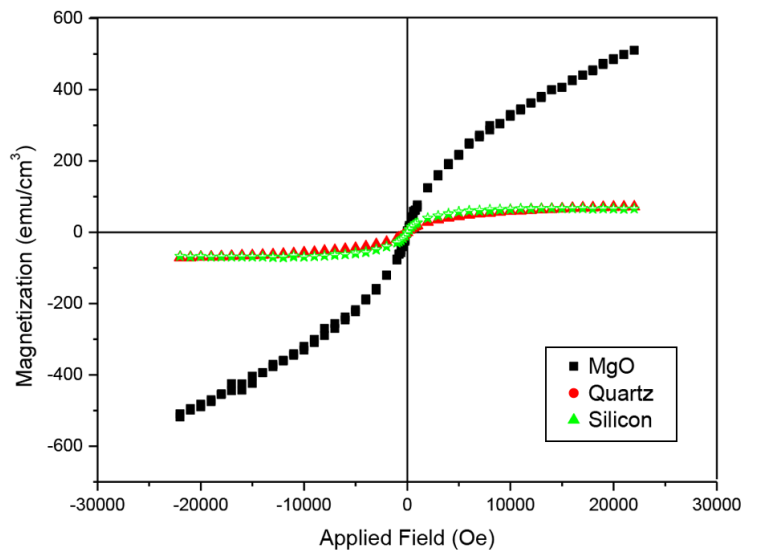

(a)

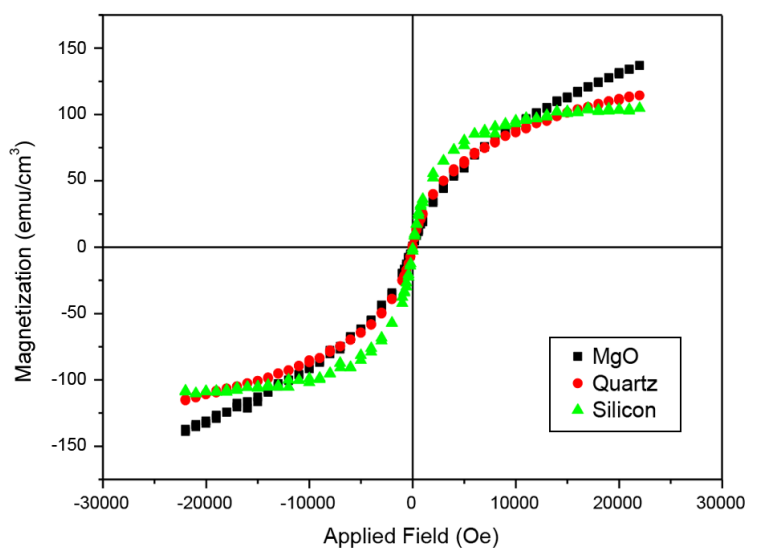

(c)

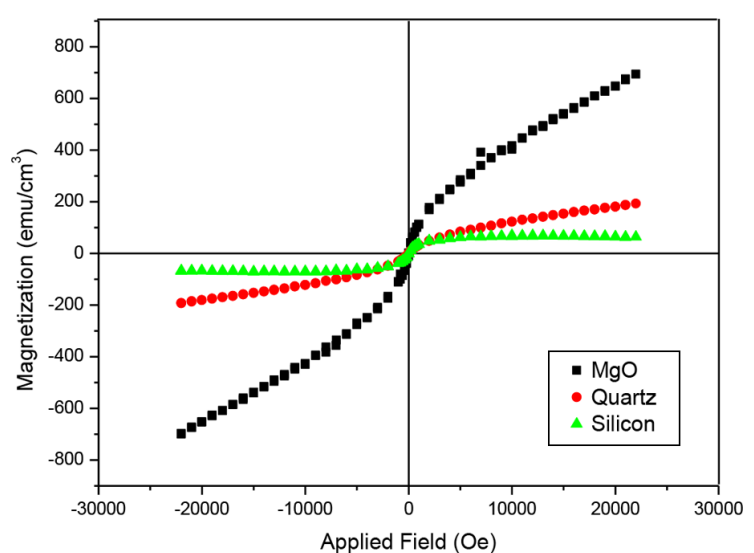

(b)

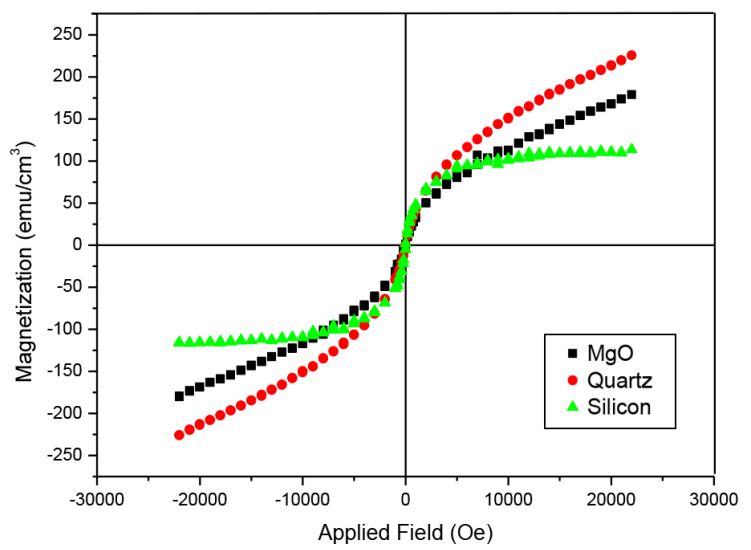

(d)

Figure 5. Magnetic field dependence of Magnetisation of as-deposited $\left(140 \mathrm{~W}, 300^{\circ} \mathrm{C}\right.$ substrate temp.) FeGa thin films measured a) parallel to the film b) perpendicular to the film c) annealed $\left(500^{\circ} \mathrm{C}\right) \mathrm{FeGa}$ thin films measured parallel to the film d) perpendicular to the film.

Table 2. The saturation magnetisation values of $140 \mathrm{~W}, 300^{\circ} \mathrm{C}$ substrate temp. deposited thin films as obtained from the VSM measurement.

\begin{tabular}{cccc}
\hline Substrate & Measurement parameters & As prepared & Annealed \\
\hline $\mathrm{MgO}$ & $\mathrm{M}_{\mathrm{s} / /}\left(\mathrm{emu} / \mathrm{cm}^{3}\right)$ & 518 & 139 \\
& $\mathrm{M}_{\mathrm{s}} \perp\left(\mathrm{emu} / \mathrm{cm}^{3}\right)$ & 707 & 182 \\
& $\mathrm{M}_{\mathrm{s}} \perp / \mathrm{M}_{\mathrm{s} / /}$ & 1.365 & 1.309 \\
& $\mathrm{M}_{\mathrm{s} / /}\left(\mathrm{emu} / \mathrm{cm}^{3}\right)$ & 79.56 & 117 \\
& $\mathrm{M}_{\mathrm{s}} \perp\left(\mathrm{emu} / \mathrm{cm}^{3}\right)$ & 204 & 229 \\
& $\mathrm{M}_{\mathrm{s}} \perp / \mathrm{M}_{\mathrm{s} / /}$ & 2.55 & 1.957 \\
& $\mathrm{M}_{\mathrm{s} / /}\left(\mathrm{emu} / \mathrm{cm}^{3}\right)$ & 64.96 & 107 \\
& $\mathrm{M}_{\mathrm{s}} \perp\left(\mathrm{emu} / \mathrm{cm}^{3}\right)$ & 86 & 119 \\
& $\mathrm{M}_{\mathrm{s}} \perp / \mathrm{M}_{\mathrm{s} / /}$ & 1.323 & 1.112 \\
\hline
\end{tabular}

of magnetization for as deposited films on $\mathrm{MgO}$ may be attributed to the presence of (111) plane which favours easy axis of magnetization. The $\mathrm{DO}_{3}$ has (311) plane present which corresponds to the hard axis of magnetization for a bec crystal as can be seen from the hysteresis loop. The miller planes in as prepared film on $\mathrm{MgO}$ exhibited increase in intensity on annealing, with both (111) and (211) planes equally increasing in intensity. The decrease in magnetization after annealing, in $\mathrm{MgO}$ substrate, could be due to the miller planes being present in opposite direction which may annihilate the magnetization achieved by both miller planes. Quasilinear loops are obtained when magnetization was measured parallel and perpendicular to the deposited film.

There is enhanced magnetisation and retention of $\mathrm{L}_{2}$ order in the film which could be attributed as an influence of $\mathrm{MgO}$ on the film. The microstrain calculation also indicated the favourability of $\mathrm{MgO}$ as a suitable substrate for Fe-Ga film growth. It has been mentioned elsewhere ${ }^{10}$ that relative 


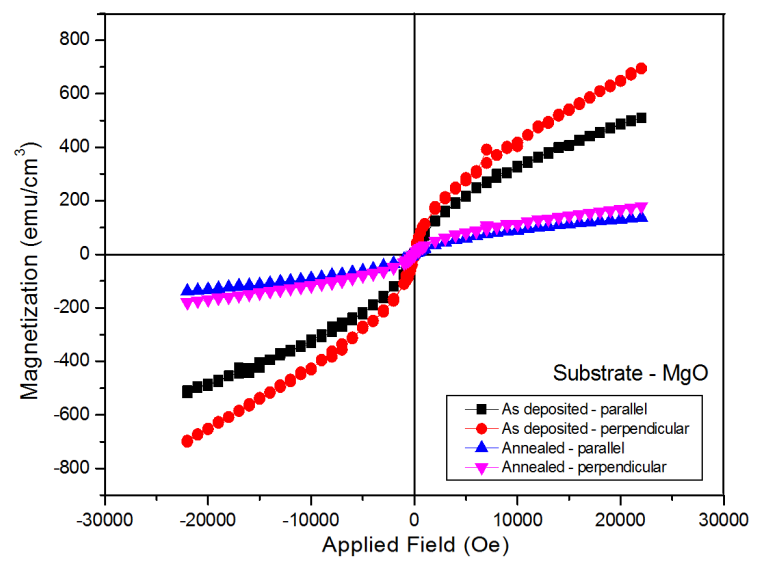

(a)

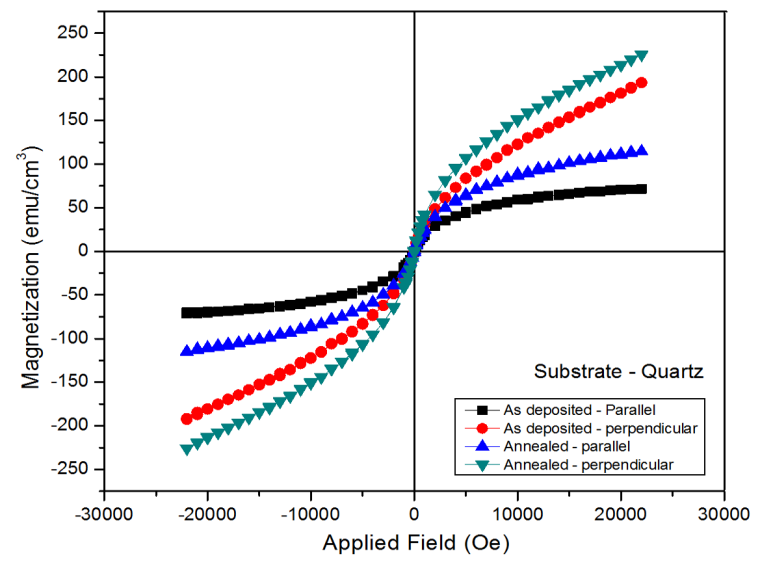

(b)

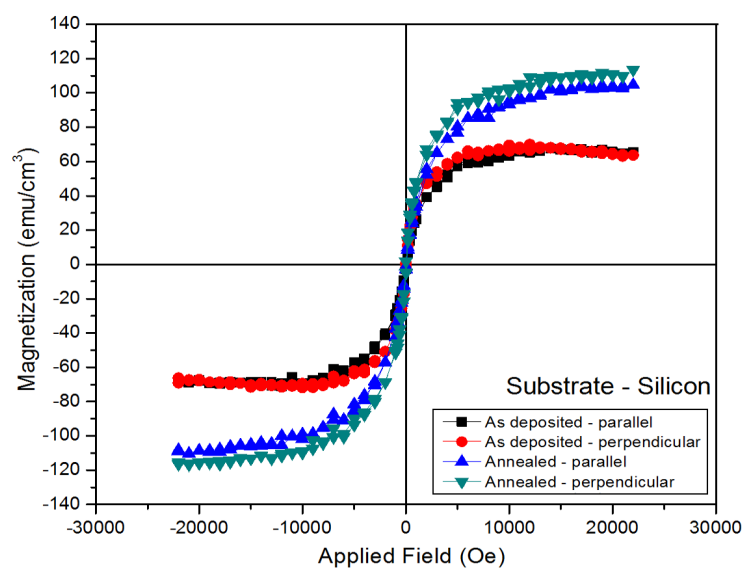

(c)

Figure 6. In plane and Out-of-plane M-H curves of as-deposited and annealed Fe-Ga thin films on different substrates a) MgO b) Quartz c) Silicon.

small lattice mismatch between $\mathrm{MgO}$ and $\mathrm{FeGa}$ (cubic with $\sim 0.7 \%$ lattice mismatch) favours good nucleation and growth of thin films.

\section{Conclusions}

The structure and magnetic properties of FeGa thin films grown by RF magnetron sputtering technique have been investigated. It was found that long-range ordered $\mathrm{DO}_{3}$ structure was formed in all sputter conditions, but for high sputter power of $140 \mathrm{~W}$ in $100 \mathrm{~nm}$ thick films, coexistence of $\mathrm{L1}_{2}$ and $\mathrm{DO}_{3}$ phases were observed. On annealing this film, lattice rearrangement occurred leading to the disappearance of $\mathrm{L}_{2}$ phase, leaving only $\mathrm{DO}_{3}$ in the film. The effect of substrates on the structure and magnetic properties were

\section{References}

1. Basantkumar RR, Stadler BJH, Robbins WP and Summers EM. Intergration of thin-film galfenol with MEMS cantilevers for magnetic actuation. IEEE Transactions on Magnetics. 2006; 42(10):3102-3104. http://dx.doi.org/10.1109/TMAG.2006.879666.

2. Lograsso TA, Ross AR, Schlagel DL, Clark AE and Wun-Fogle M. Structural transformations in quenched Fe-Ga alloys. Journal also studied and it was observed that the $\mathrm{MgO}$ substrate favoured higher magnetization when compared to $\mathrm{Si}$ and Quartz substrates. An anomalous behaviour was observed when $100 \mathrm{~nm}$ thick $300{ }^{\circ} \mathrm{C}$ deposited film on Si substrate was annealed. The films on $\mathrm{MgO}$ and Quartz retained $\mathrm{L}_{2}$ order and there was enhanced magnetization for films on MgO substrate.

\section{Acknowledgements}

The authors RTR and NLR would like to thank University Grants Commission - Inter University Accelerator Centre, New Delhi for the financial support provided through the UGC - IUAC project (IUAC/XIII.7/UFR-51311/2677).

of Alloys and Compounds. 2003; 350(1-2):95-101. http://dx.doi. org/10.1016/S0925-8388(02)00933-7.

3. Gaudet JM, Hatchard TD, Farrell SP and Dunlap RA. Properties of Fe-Ga based powders prepared by mechanical alloying. Journal of Magnetism and Magnetic Materials. 2008; 320(6):821-829. http://dx.doi.org/10.1016/j.jmmm.2007.08.029.

4. Javed A, Szumiata T, Morley NA and Gibbs MRJ. An investigation of the effect of structural order on magnetostriction and magnetic 
behaviour of Fe-Ga alloy thin films. Acta Materialia. 2010; 58(11):4003-4011. http://dx.doi.org/10.1016/j.actamat.2010.03.023.

5. Basumatary H, Palit M, Arout Chelvane J, Pandian S, Manivel Raja $\mathrm{M}$ and Chandrasekaran V. Structural ordering and magnetic properties of $\mathrm{Fe}_{100-\mathrm{x}} \mathrm{Ga}_{\mathrm{x}}$ alloys. Scripta Materialia. 2008; 59(8):878881. http://dx.doi.org/10.1016/j.scriptamat.2008.06.034.

6. Zhang MC, Gao XX, Jiang HL, Qiao Y and Zhou SZ. Effect of $\mathrm{Ga}$ content on the magnetostriction and microstructure of Fe-Ga ribbons'. Journal of Alloys and Compounds. 2007; 431(1-2):42-44. http://dx.doi.org/10.1016/j. jallcom.2006.05.093.

7. Morley NA, Yeh SL, Rigby S, Javed A and Gibbs RJ. Development of a cosputter-evaporation chamber for Fe-Ga films. Journal of Vacuum Science \& Technology. A, Vacuum, Surfaces, and Films. 2008; 26(4):581-586. http://dx.doi.org/10.1116/1.2924416.

8. Javed A, Morley NA and Gibbs MRJ. Structure, magnetic and magnetostrictive properties of as-deposited $\mathrm{Fe}-\mathrm{Ga}$ thin films. Journal of Magnetism and Magnetic Materials. 2009; 321(18):2877-2882. http://dx.doi.org/10.1016/j.jmmm.2009.04.039.

9. Butera A, Gomez J, Barnard JA and Weston JL. 'Magnetic anisotropy in $\mathrm{Fe}_{81} \mathrm{Ga}_{19} / \mathrm{MgO}$ (100) films sputtered at different powers. Physica B, Condensed Matter. 2006; 384(1-2):262-264. http://dx.doi.org/10.1016/j.physb.2006.06.005.

10. Butera A, Gomez J, Weston JL and Barnard JA. Growth and magnetic characterization of epitaxial $\mathrm{Fe}_{81} \mathrm{Ga}_{19} / \mathrm{MgO}(100)$ thin films. Journal of Applied Physics. 2005; 98(3):033901. http:// dx.doi.org/10.1063/1.1996829.

11. Kawamiya N, Adachi K and Nakamura Y. Magnetic properties and mossabauer investigations of Fe-Ga alloys. Journal of the Physical Society of Japan. 1972; 33(5):1318-1327. http://dx.doi. org/10.1143/JPSJ.33.1318.

12. Adolphi B, McCord J, Bertram M, Oertel C-G, Merkel U, Marschner U, et al. Improvement of sputtered Galfenol thin films for sensor applications. Smart Materials and Structures. 2010; 19(5):055013. http://dx.doi.org/10.1088/0964-1726/19/5/055013.

13. Butera A, Weston JL and Barnard JA. Ferromagnetic resonance of epitaxial $\mathrm{Fe}_{81} \mathrm{Ga}_{19}$ (110) thin films. Journal of Magnetism and Magnetic Materials. 2004; 284:17-25. http://dx.doi. org/10.1016/j.jmmm.2004.06.015.

14. Weston JL, Butera A, Lograsso T, Shamsuzzoha M, Zana I, Zangari G, et al. Fabrication and characterization of $\mathrm{Fe}_{81} \mathrm{Ga}_{19}$ thin films. IEEE Transactions on Magnetics. 2002; 38(5):28322834. http://dx.doi.org/10.1109/TMAG.2002.802468. 